\title{
Monospecific helminth and arthropod infections in an urban population of brown rats from Doha, Qatar
}

\author{
M.A. Abu-Madi ${ }^{1 *}$, J.W. Lewis ${ }^{2}$, M. Mikhail ${ }^{3}$, M.E. El-Nagger ${ }^{3}$ \\ and J.M. Behnke \\ ${ }^{1}$ Department of Applied Sciences, Faculty of Technology, Qatar \\ University, PO 2713, Doha, Qatar: ${ }^{2}$ School of Biological Sciences, Royal \\ Holloway, University of London, Egham, Surrey, TW20 OEX, UK: \\ ${ }^{3}$ Department of Health-Affairs, Ministry of Municipal Affairs and \\ Agriculture, Doha, Qatar: ${ }^{4}$ School of Life and Environmental Sciences, \\ University of Nottingham, Nottingham, NG7 2RD, UK
}

\begin{abstract}
Parasitic infections were studied for the first time in an urban population of brown rats (Rattus norvegicus) from Doha. Only one species of helminth was found, the cestode Hymenolepis diminuta, and one ectoparasite, the flea Xenopsylla astia, from a sample size of 136 rats (52 males and 84 females). The prevalence of $H$. diminuta was $17.6 \%$, increasing with host age but not in relation to host sex nor season of capture. Host age was a key factor in influencing abundance of infection, although there was a significant three-way interaction with season and host sex arising through heavy infections in juvenile male rats in the summer. The prevalence of X. astia was $45.6 \%$, although both prevalence and abundance of infestations were season and host age dependent. In the winter prevalence and abundance were similar in both host age and sex groups, but in the summer both parameters of infestation were markedly higher among juveniles compared with adults. We found evidence for some association between these two species: $H$. diminuta was more prevalent among rats with fleas than among those without, although this association was season-, and independently sex- and age-dependent. There were no quantitative interactions and reasons for this are discussed in relation to the foraging and breeding behaviour of the brown rat in Qatar.
\end{abstract}

\section{Introduction}

Although the ecology of helminth parasites in small rodent populations inhabiting temperate regions of Europe are well documented (Kisielewska, 1970; Haukisalmi et al., 1988; Montgomery \& Montgomery, 1990; Behnke et al., 1993; Webster \& MacDonald, 1995; AbuMadi et al., 1998) reports on small rodent parasites from the Middle East and African countries usually represent no more than species lists. Despite extensive information

*Fax: 009744655749

E-mail: abumadi:@qu.edu.qa on the helminth fauna (Myers et al., 1962; Sinniah, 1979; Zakaria \& Zaghloul, 1982; Seong et al., 1995), there is relatively little comparable data on the ecology of helminths in rodents living in hostile and arid regions in the Middle East and Africa (Greenberg, 1969; Erhardova-Kotrla \& Daniel, 1970; Werthein \& Greenberg, 1970). Among the more comprehensive studies on brown rats from arid regions in which ecological factors affecting parasite burdens were taken into account are those from Egypt (Fahmy et al., 1969) and Kuwait (Zakaria \& Zaghloul, 1982). With the exception of Behnke et al. (2000) almost nothing is known about the relative factors responsible for variation in the parasite infra and 
component community structures of small rodents inhabiting these regions.

Three species of commensal rodents are distributed worldwide: the brown rat (Rattus norvegicus), the black rat (Rattus rattus) and the house mouse (Mus musculus) (Brooks \& Rowe, 1987). The Norway or brown rat is a gregarious species and under very favourable conditions colonies of several hundred strong may develop. Norway rats are the common urban and rural rats of temperate regions of North America and Europe, living both indoors and outdoors. In tropical areas, Norway rats mainly exist in coastal seaports and irrigated agricultural areas. In towns and villages they occur in garbage dumps and other refuse, around cesspits, in sewer systems and storm drains (Brooks \& Rowe, 1987).

Almost nothing is known about the diseases of the brown rat in Qatar. The diversity of their distribution in both urban and rural areas in particular, their exposure to and exploration of different food materials of both human and non-human origin, and other factors affecting their ecology may expose them to a diversity of parasitic infections. We reported here the results of our preliminary investigations into the diversity of parasitic infections of the most common rodent in Qatar, the brown rat, Rattus norvegicus and their possible zoonotic and public health importance. Our second objective is to test the hypothesis that in addition to intrinsic factors (host sex and age), an extrinsic factor (season) plays a major role in determining parasite burdens.

\section{Materials and methods}

Collection of rats and parasites

Trapping was carried out in the vicinity of a food market at Abu-Hammour on the outskirts of Doha for 6 days at 2-month intervals from June 1998 to April 1999. Fifty cage-traps, each provided with cheese and tuna for prebaiting, were used on each trapping night.

Rats were retrieved from traps and killed by exposure to a piece of chloroform-soaked cotton wool. For each rat examined, the date of trapping, body length (head and body), and sex were noted. For analysis, rats were separated into two age-weight groups, juveniles $(<100 \mathrm{~g})$ and adults $(>150 \mathrm{~g})$, as previously described by Brooks \& Rowe (1987) and season was separated into summer (April-August) and winter (October-February). Rats, including the ears, were examined for ectoparasites (fleas, lice, mites and ticks) and collected by fine-toothcombing. Ectoparasite samples were also collected from the killing bag, fixed in $10 \%$ formalin and each species later identified by microscopical examination. The alimentary canal was then removed for further examination and the eviscerated body weight of each animal was recorded. The small intestine from pyloric sphincter to caecum was separated from the surrounding fat tissue and placed in a Petri dish containing physiological saline. The small intestine was opened longitudinally and examined for helminth parasites under a low power binocular microscope. Parasites were carefully removed, identified and counted. The prevalence (percentage of rats infected), mean abundance of infection (including uninfected rats) and the frequency distribution of parasites were then calculated.

\section{Statistical analysis}

Frequency distributions of individual species were tested for goodness of fit to negative binomial, positive binomial and Poisson models by $\chi^{2}$ as described by Elliott (1977) and the negative binomial exponent $k$ is given as appropriate. The variance to mean ratio (Index of Dispersion $I$ ) is also given. The degree of aggregation in the data was calculated by the Index of Discrepancy (D) as described by Poulin (1993) (a value of 0 indicates an even distribution of counts across all hosts and a value of 1 indicates all parasites aggregated in a single host).

Prevalence was analysed by maximum likehood techniques based on log linear analysis of contingency tables implemented by the software package, Statgraphics Version 7. Beginning with the most complex model, involving all possible main effects and interactions, those combinations which did not contribute significantly to explaining variation in the data were eliminated stepwise beginning with the highest-level interaction. A minimum sufficient model was then obtained, for which the likelihood ratio of $\chi^{2}$ was not significant, indicating that the model was sufficient in explaining the data.

Parasite burdens were expressed as geometric means $(\mathrm{GM}) \pm 95 \%$ confidence limits (CL) of eggs per gram of faeces (epg) because the data were overdispersed (Elliott, 1977; Dash et al., 1988). In some cases arithmetic mean and standard errors of the means are also provided. These means reflect the abundance of infection as defined by Margolis et al. (1982) and include all subjects within the specified group, infected and not infected, for which relevant data were available. Abundance data were analysed by GLIM (a statistical system for generalized linear interactive modelling; GLIM 4, PC version, Royal Statistical Society, 1993) as described previously, using models with normal errors after normalization of the data by $\log _{10}(x+1)$ transformation (Crawley, 1993; De Clercq et al., 1997, Abu-Madi et al., 1998). Host sex (two levels, male or female), host age (two levels, juvenile or adult) and season (two levels, winter or summer) were entered as factors. For models with normal errors the change in deviance is divided by the scale parameter and the result divided by the change in degrees of freedom (df) following each deletion, to give a variance ratio, $F$.

For quantitative analysis of associations between parasites, we saved the residuals from minimum sufficient three- or two-way ANOVAs, as appropriate for individual species, in order to control for established differences between the seasons, host sex and age. These were examined by rank order correlation analysis (Spearman's).

\section{Results}

A total of $136 R$. norvegicus, 52 males and 84 females, were trapped of which $44.9 \%(n=61,18$ males and 43 females) were classed as juveniles. Sixty two rats were captured in the summer (season 1) and 74 in the winter (season 2) periods. 
Table 1. Minimum sufficient maximum likelihood statistical model of factors affecting the prevalence of infection with Hymenolepis diminuta.

\begin{tabular}{|c|c|c|c|}
\hline Sources of variation ${ }^{1}$ & $\begin{array}{l}\text { Degrees of } \\
\text { freedom }\end{array}$ & $\begin{array}{c}\mathrm{LR}^{2} \\
\chi^{2}\end{array}$ & $P^{3}$ \\
\hline Age $\times$ infection & 1 & 10.236 & 0.0014 \\
\hline Season $\times$ age & 1 & 4.611 & 0.0318 \\
\hline Sex & 1 & 7.601 & 0.0058 \\
\hline $\begin{array}{l}\text { Goodness-of-fit of the minimum } \\
\text { sufficient model specified by the } \\
\text { interactions listed above }\end{array}$ & 9 & 9.363 & $0.405^{4}$ \\
\hline
\end{tabular}

${ }^{1}$ Four components were entered season (winter or summer), sex (male or female), age (juvenile or adult) and infection (present or absent).

${ }^{2}$ Likelihood ratio Chi squared.

${ }^{3}$ Probability that excluding the combination in source of variation will make a significant difference to the model.

${ }^{4}$ Probability that the data does not differ significantly from the minimum sufficient model described by the principal interactions listed under sources of variation.

\section{Total species richness}

Surprisingly, only one helminth species (Hymenolepis diminuta) was recovered (prevalence $=17.6 \%$ ). Forty five percent of the rats also carried the flea Xenopsylla astia.

\section{Hymenolepis diminuta}

Twenty four rats harboured $H$. diminuta $((17.6 \%) ; 11$ male $(21.2 \%)$ and 13 female $(15.5 \%))$. Analysis of the prevalence of infection in adult rats in respect of three factors, season (two levels), sex (two levels) and age (two levels) gave a minimum sufficient model which incorporated only one term involving infection, the age $\times$ infection interaction (table 1). Adult rats had a higher overall prevalence of infection compared with juveniles, but there was an exception among male rats captured in summer (fig. 1A), when prevalence was almost identical among juveniles and adults. In fact, this relatively high prevalence among male juveniles arose through a small sample size in this season in which two out of the nine male juvenile rats carried $H$. diminuta and one of which carried the heaviest parasite burden of all (45 worms). There was no overall effect of host sex on prevalence and no difference in prevalence between the seasons (table 1 ).

The arithmetic mean worm burden across the whole dataset was $1.7 \pm 0.5(\mathrm{GM}=0.4,95 \%$ CL 0.3-0.7) and the variance/mean ration $I=18.0$. The tapeworm $H$. dimin$u t a$ was highly aggregated in the host population $(D=$ $0.89 ; k=0.099 \pm 0.026$ and $\chi^{2}=2.3, d f=2, P=\mathrm{NS}$ ). For this reason, abundance of infection was analysed by a three-way ANOVA in GLIM on $\log _{10}(x+1)$ transformed data. This analysis revealed that the three-way interaction was just significant $(F 1,129=4.359,0.05>P>$ $0.025)$. No other interactions were significant but there was also a significant strong main effect of age $(F 1,133=7.271, P<0.01)$. Figure $1 \mathrm{~b}$ shows that the overall picture was compounded by the unusually high worm burden in the juvenile male rats in summer. With this taken into account, the age effect arose because of
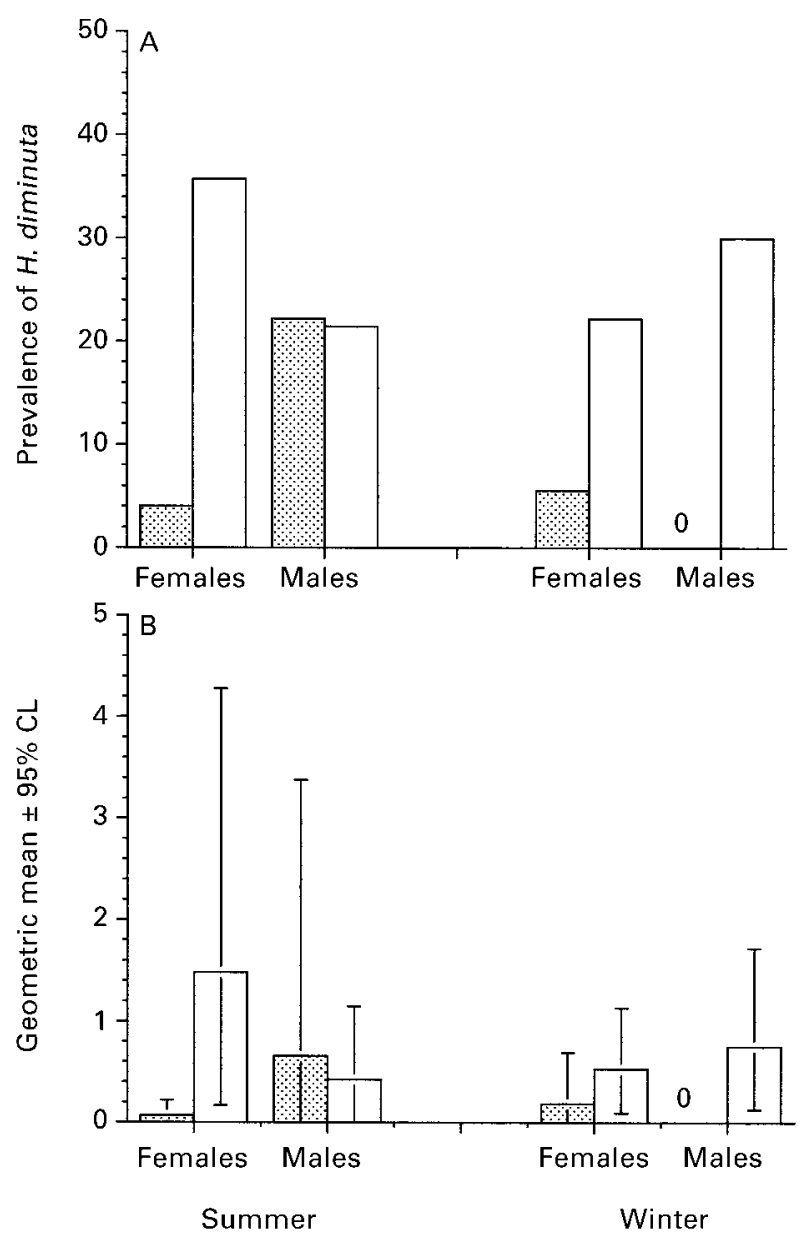

Fig. 1. Variation in prevalence (A) and abundance (B) of infection with Hymenolepis diminuta, in two age classes of male and female rats sampled in the summer and winter seasons (圈, juveniles; $\square$, adults).

higher worm burdens in adult compared with juvenile rats in the winter and among adult females in the summer. There was no seasonal effect nor any significant interactions with season apart from the three-way interaction.

\section{Xenopsylla astia}

Sixty two rats harboured X. astia (45.6\%). Analysis of prevalence generated a minimum sufficient model with two terms as shown in table 2, one of which incorporated infection; there was a significant interaction between season and age on infection. Although in the winter rats of both sexes and both age classes showed much the same prevalence of infestation, in the summer months juveniles of both sexes exhibited a higher prevalence compared with adults (fig. 2A).

The overall arithmetic mean for abundance was $2.8 \pm$ $0.5(\mathrm{GM}=1.2,95 \% \mathrm{CL} 0.9-1.6)$ and a variance/mean ratio $(I)$ of 10.4 , but the distribution did not conform to the negative binomial $\left(k=0.268 \pm 0.046, \chi^{2}=12.8, d f=\right.$ 
Table 2. Minimum sufficient maximum likelihood statistical model of factors affecting the prevalence of infection with Xenopsylla astia.

\begin{tabular}{|c|c|c|c|}
\hline Sources of variation ${ }^{1}$ & $\begin{array}{l}\text { Degrees of } \\
\text { freedom }\end{array}$ & $\begin{array}{c}\mathrm{LR}^{2} \\
\chi^{2}\end{array}$ & $P^{3}$ \\
\hline Season $\times$ age $\times$ infection & 1 & 9.774 & 0.0018 \\
\hline Sex & 1 & 7.601 & 0.0058 \\
\hline $\begin{array}{l}\text { Goodness-of-fit of the minimum } \\
\text { sufficient model specified by the } \\
\text { interactions listed above }\end{array}$ & 9 & 7.614 & $0.368^{4}$ \\
\hline
\end{tabular}

${ }^{1}$ Four components were entered season (winter or summer), sex (male or female), age (juvenile or adult) and infection (present or absent).

${ }^{2}$ Likelihood ratio Chi squared.

${ }^{3}$ Probability that excluding the combination in source of variation will make a significant difference to the model.

${ }^{4}$ Probability that the data does not differ significantly from the minimum sufficient model described by the principal interactions listed under sources of variation.
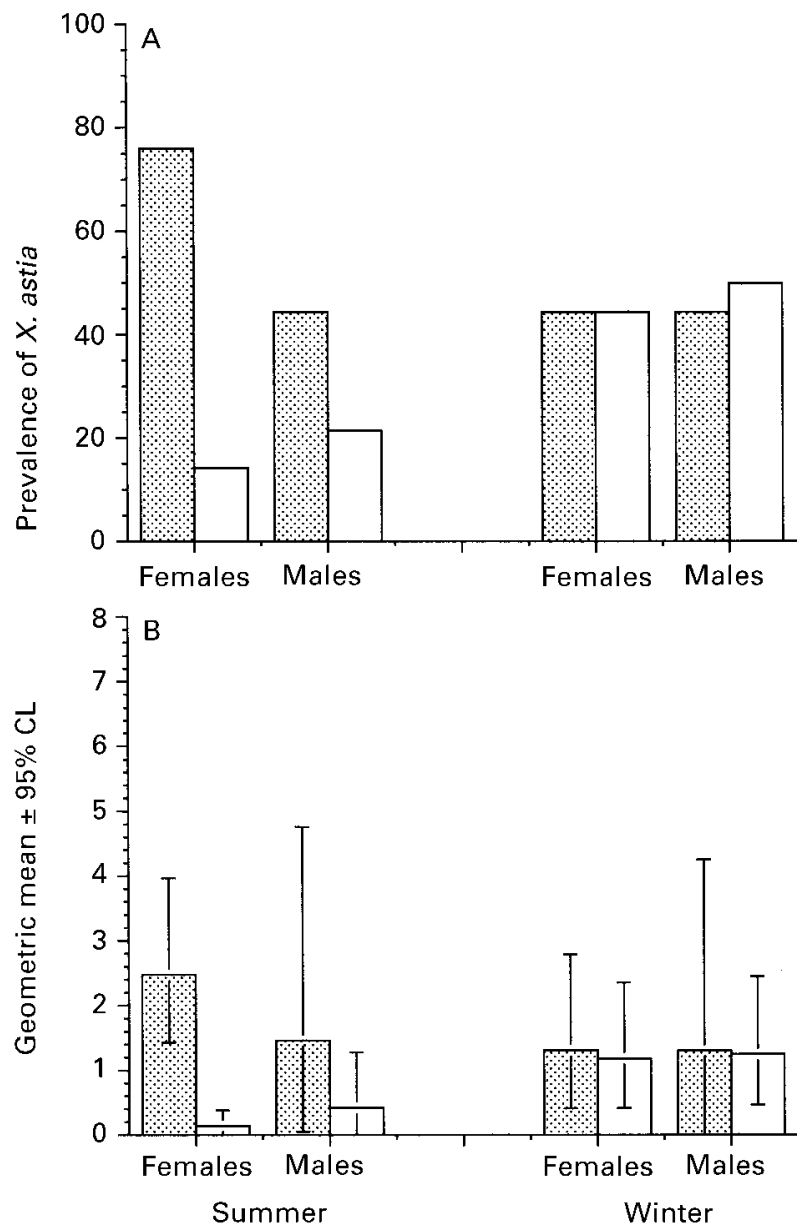

Fig. 2. Variation in prevalence (A) and abundance (B) of infection with Xenopsylla astia, in two age classes of male and female rats sampled in the summer and winter seasons (畨, juveniles; $\square$, adults).
5, $P<0.025 ; D=0.74$ ), although this was the closest fit of the distributions tested. We analysed the abundance of flea infestations by a three-way ANOVA in GLIM on $\log _{10}(x+1)$ transformed data. This analysis revealed that there was a significant main effect of age $(F 1,133=6.790$, $P<0.01)$ and this is apparent in fig. $2 \mathrm{~B}$ where the means are higher in juvenile compared with adult rats throughout. However, there was also a significant two-way interaction between season and age $(F 1,131=6.768, P<$ 0.01 ) and this arose because the means of the two age groups were close in the winter (GM for juveniles and adults $=1.3$ and 1.2, respectively) contrasting with the much lower mean among adults and higher mean among juveniles in the summer (GM for juveniles and adults $=2.2$ and 0.3 , respectively).

\section{Association between $\mathrm{H}$. diminuta and X. astia}

We tested the idea that $H$. diminuta and $X$. astia may be associated with each other in particular animals. First we conducted a log-linear analysis using the presence/ absence data for both species and incorporating all the factors known to influence them. The outcome is summarized in table 3 and this shows that three interactions are required for the minimum sufficient model. Two of these interactions involve both parasites but whilst they are independent of each other, neither is independent of other factors. Thus, whilst $H$. diminuta was more prevalent among rats with fleas $(21.0 \%)$ than among those without fleas (14.9\%), this overall finding was compounded by a marked seasonal difference; the prevalence of $H$. diminuta was higher among rats carrying fleas in the winter and lower in the summer (fig. 3B, the season $\times H$. diminuta $\times X$. astia interaction). The second interaction involving both species was more complex and dependent on both host sex and age. As can be seen from fig. $3 \mathrm{~A}$, prevalence of $H$. diminuta was higher in adult rats of both sexes among individuals

Table 3. Minimum sufficient maximum likelihood statistical model of association between Hymenolepis diminuta and Xenopsylla astia with season, sex and host age taken into account.

\begin{tabular}{|c|c|c|c|}
\hline Sources of variation ${ }^{1}$ & $\begin{array}{l}\text { Degrees of } \\
\text { freedom }\end{array}$ & $\begin{array}{c}\mathrm{LR}^{2} \\
\chi^{2}\end{array}$ & $P^{3}$ \\
\hline Sex $\times$ age $\times H$. diminuta $\times X$. astia & 1 & 5.232 & 0.022 \\
\hline Season $\times H$. diminuta $\times X$. astia & 1 & 6.461 & 0.011 \\
\hline Season $\times$ age $\times X$. astia & 1 & 5.605 & 0.018 \\
\hline Goodness-of-fit of the minimum & 10 & 5.116 & $0.883^{4}$ \\
\hline
\end{tabular}

sufficient model specified by the interactions listed above

\footnotetext{
${ }^{1}$ Five components were entered season (winter or summer), sex (male or female), age (juvenile or adult) and infection with $H$. diminuta (present or absent) and infestation with X. astia (present or absent).

${ }^{2}$ Likelihood ratio Chi squared.

${ }^{3}$ Probability that excluding the combination in source of variation will make a significant difference to the model.

${ }^{4}$ Probability that the data does not differ significantly from the minimum sufficient model described by the principal interactions listed under sources of variation.
} 


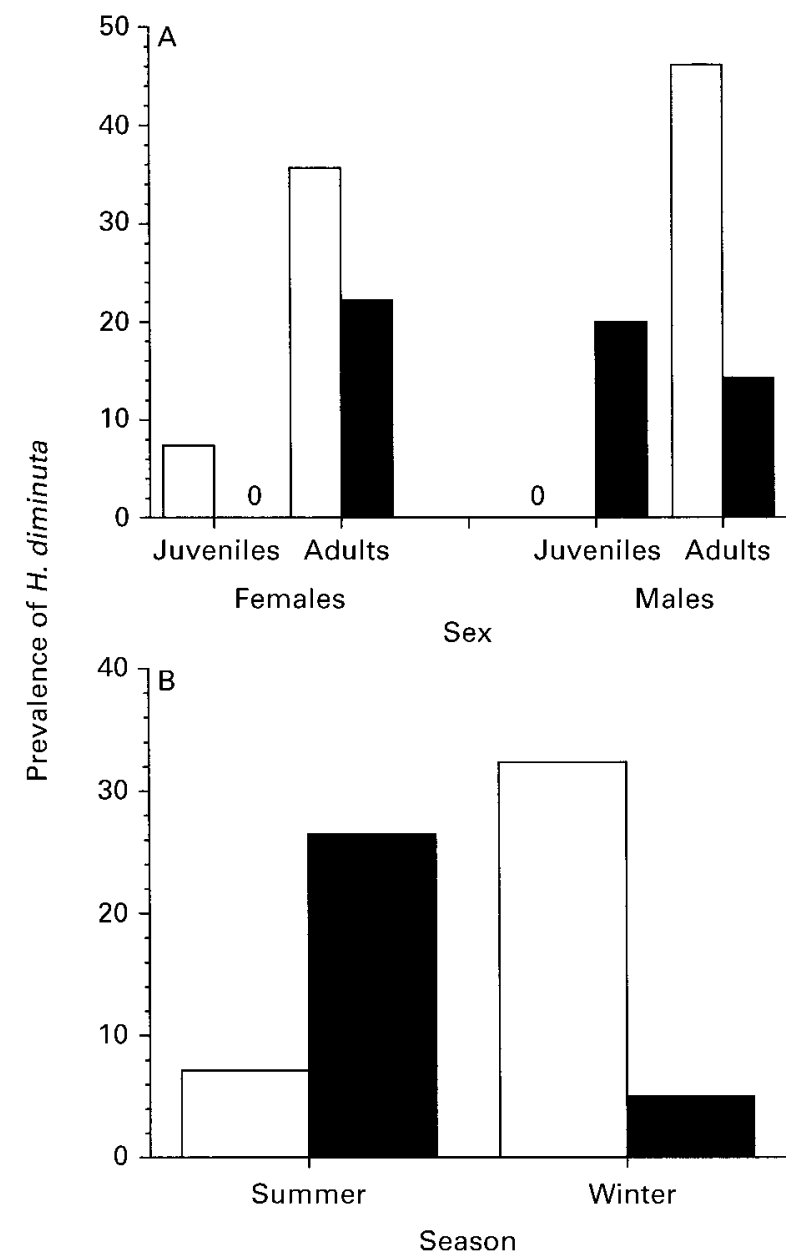

Fig. 3. Host sex- and age-dependent (A) and season-dependent (B) associations between Hymenolepis diminuta and Xenopsylla astia in rats ( $\mathbf{\square}$, rats without fleas; $\square$, rats with fleas).

carrying fleas compared with those without fleas. However, among juvenile rats $H$. diminuta was found only among females with fleas $(2 / 27)$ and among males without fleas (2/10). However, the last class was relatively small, as was that of juvenile males without fleas $(n=8)$.

Quantitative interactions were first examined by Spearman's rank order correlational analysis using raw abundance data from the 13 rats which carried both species. This gave $r_{s}=0.38, n=13, P=$ NS. However, the abundance of each species was shown earlier to be affected by various combinations of factors, and hence associations may have been obscured by the compounding effect arising from seasonal, host age and sex influences on parasite burdens. Hence, in the next step, we ran a correlational analysis on the residuals from minimum sufficient ANOVAs in GLIM for each species (to control for the compoundings effects of age, sex and season, where these were significant). This analysis did not support the existence of quantitative interactions between $H$. diminuta and X. astia $\left(r_{s}=0.187\right.$, $n=13, P=\mathrm{NS})$.

\section{Discussion}

Although the helminth parasites of the brown rat, R. norvegicus, from Egypt (Fahmy et al., 1969) and Kuwait (Zakaria \& Zaghloul, 1982) have been studied previously, none of these studies provide detailed quantitative information on helminth component community structures, range of variation in infracommunity structures nor probe the underlying ecology of the host-parasite systems involved in depth. We are not aware of any detailed quantitative data on parasitic infection in brown rats from Arabian Gulf countries which consider such effects as host age, sex and seasonal fluctuations in parasite numbers that contribute to a picture of the ecological relationships between the hosts and parasites concerned. Our quantitative analyses of parasite burdens therefore make novel contributions to the understanding of the ecology of the parasitic infections in an urban population of brown rats inhabiting the harsh, arid environment in the outskirts of Doha, Qatar.

Previous studies on the helminth parasites of $R$. norvegicus (Fahmy et al., 1969 in Egypt; Seng et al., 1979 in Malaysia; Zakaria \& Zaghloul, 1982 in Kuwait; Seong et al., 1995 in Korea; Webster \& MacDonald, 1995 in the UK) and R. rattus (Seng et al., 1979 and Sinniah, 1979 in Malaysia; Udonsi, 1989 and Mafiana et al., 1997 in Nigeria) have demonstrated the presence of a large parasite fauna and wide helminth species diversity in host populations, primarily dominated by nematodes and cestodes and to a lesser extent by trematodes and acanthocephalans (Fahmy et al., 1969). Consistent with our findings, the cestode $H$. diminuta has, in general, been found to be a dominant member of the helminth communities of $R$. norvegicus, especially in rat populations examined from a variety of habitats in Egypt (Fahmy et al., 1969) where up to 67\% of rats were infected with $H$. diminuta and up to $59.2 \%$ of the rat population harboured multiple infections comprising six trematode, six nematode, three cestode and one acanthocephalan species. Zakaria \& Zaghloul (1982) also recorded multiple helminth infections in up to $40 \%$ of $R$. norvegicus in Kuwait and up to $20 \%$ of rats were infected with $H$. diminuta in association with four cestode and three nematode species. Seong et al. (1995) found up to $32.5 \%$ of $R$. norvegicus infected with $H$. diminuta in farm habitats in Korea and this included concurrent infections in 83.7\% of rats with at least one other cestode and nematode species. In their survey in the UK, Webster \& MacDonald (1995) reported that up to $22 \%$ of farm $R$. norvegicus were infected with $H$. diminuta together with multiple infections of up to five nematode and two other cestode species. However, the helminth community in the UK study was dominated by nematode species especially the pinworm Syphacia muris with a prevalence of $67 \%$. Nematodes were also dominant in Egyptian rats (Fahmy et al., 1969) where prevalences of $78 \%$ and $65.9 \%$ were recorded for trichuroid and spiruroid species respectively.

The monoxenous nature of the life cycle of nematodes may be responsible for this parasitic group dominating the helminth community of small mammals worldwide, especially rodents (Lewis, 1968, 1987; Lewis \& Twigg, 1972; Behnke et al., 2000). Behnke's work in Sinai, Egypt 
recorded six species of helminths in Acomys sp. with the spirurids, which are heteroxenous, being the dominant species present in spiny mice. Perhaps surprisingly, the trend in Qatar is different as no nematode infections were found to occur in brown rats and the helminth component community was dominated by a cestode. The most interesting aspect of our findings was the single infection of $R$. norvegicus by $H$. diminuta. The results were particularly significant not only because $H$. diminuta is a potential source of infection to the human population in Doha but also this is the first report of a single helminth species infection in a wild host population and hence of particular interest to parasitologists working in the field of community ecology and epidemiology. This tapeworm, $H$. diminuta can be transmitted from rodents to humans, particularly children (Welch, 1972; Chomel, 1992; Tena et al., 1998). Infection of mammalian hosts, including humans, occurs when infected intermediate hosts (usually flour beetles) are inadvertently consumed in food. Furthermore, one ectoparasite, the flea X. astia, was also identified and this is particularly significant as $X$. astia is also a zoonotic parasite capable of transmitting diseases from rodents to humans (Acha \& Szyfres, 1987; Brooks \& Rowe, 1987; Webster \& Macdonald, 1995).

The study described in this paper focused on the contibution of one extrinsic (season) and two intrinsic (age and sex) factors in attempting to explain the prevalence of, and variation in abundance of, $H$. diminuta and X. astia among brown rats from Qatar. These factors interact in various combinations to shape the component of community structure in a given habitat at a specific time (Abu-Madi et al., 1998, 2000; Behnke et al., 1999, 2000). Seasonal variation in the prevalence and abundance of $H$. diminuta throughout the year is influenced by a combination of factors, including the variation in ingestion rates of infective stage and host population changes, breeding period, age, sex and foraging activity of hosts. Our statistical analysis revealed that neither $H$. diminuta nor $X$. astia showed any clear independent seasonal patterns in prevalence. Both showed similar prevalence in the summer and the winter although the pattern was different in some subsets. There was no seasonal effect on abundance of $H$. diminuta infection nor any significant interactions with season apart from the three-way interaction. In the winter, prevalence and abundance of X. astia were very similar in both sexes and both age groups, but in the summer both parameters of infestation were markedly higher among juveniles compared with adults.

Perhaps surprisingly, host sex contributed little to the abundance of $H$. diminuta infection other than through three-way interaction with season and host age arising principally through exceptionally heavy infections in juvenile male rats in the summer. In this respect our data differ from other studies reporting significant sex differences, in which males appear to be more susceptible to $H$. diminuta infection than female rats (Mafiana et al., 1997). Such differences between the sexes may result from two factors. Firstly, males tend to range further, which may increase their exposure to infection. Secondly, immunocompetence is generally impaired by male hormones, but enhanced by female hormones (Healing \& Nowell, 1985; Bundy, 1988).
Although body weight is not the most accurate biometric indicator of age in small mammals, a number of previous works have used this to indicate host age (Lewis, 1968; Morris, 1972; Gregory, 1992; Webster \& MacDonald, 1995; Mafiana et al., 1997). Host age has a significant effect upon $H$. diminuta infections, with adult rats showing higher prevalence and being more heavily infected than juvenile rats except for juvenile males in summer. In the latter case, the juveniles are actively foraging and feeding on the grain beetles and other insects serving as intermediate hosts. Such age-related differences could be related to older rats receiving a longer exposure time to infective stages and the longevity of $H$. diminuta in its normal mammalian host. Hymenolepis diminuta, once established in its host, can live as long as its host (Read, 1967) and parasite burdens would be expected to accumulate with increasing exposure and age. Moreover, low intensity infections such as those found here are not controlled immunologically, and hence worms will accumulate with age in the population as, with increasing age, more and more rats become exposed and infected (Andreassen et al., 1999).

In the case of $X$. astia, there was no clear seasonal pattern of infestation. Older rats showed a lower prevalence in the summer compared with the winter, whilst prevalence was unaltered (males) or even increased (females) among juveniles. This result might be related to a transfer of fleas from adult to juvenile rats in the immediate post-breeding season in early summer, i.e. March-April in Qatar. There appears to be no relationship between prevalence and abundance of infestation of rats with fleas and host size/population density as reported by Rifaat et al. (1969) in Egypt. However, levels of infestation of fleas are maintained in both adult and juvenile rats during the summer and winter periods in Qatar. This suggests that rats, which become less active in summer, inhabit underground burrows with more or less constant conditions of temperature and humidity, which favour the breeding of fleas (Kansouh et al., 1990).

The prevalence and abundance of helminths may also be influenced by various types of associations between species of parasites, which can be both synergistic (positive) and antagonistic (negative). Such associations can arise for ecological/behavioural reasons, although there remains a possibility that the host immune system may also be involved. Analysis of associations between the tapeworms and fleas established that $H$. diminuta was more common among rats with fleas compared with rats without fleas, but this general finding was compounded by influences from both extrinsic (seasonal) and intrinsic (host age and sex) factors. The low prevalence of $H$. diminuta among juvenile rats with $X$. astia (the exception was male juveniles in the summer) is not unexpected given overall low prevalence among juveniles. Thus, the interaction with season arose mainly because $H$. diminuta was more common in winter in adult rats of both sexes infested with fleas. In the summer, the apparent reversal of this association, when more rats without fleas seemed to harbour the tapeworms, may have arisen through low sample sizes with just three adult males and two adult females being detected as infested with fleas and, of these, one male and no females carried the tapeworm. 
This paper has reported an exceptional data set, based on only one helminth and one arthropod species, parasitic on wild rats living in an urban enviroment in a hot and arid region in the Middle East. Our study contributes to the growing wealth of information on the range and variation in the component community structures of metazoan parasites in wild rodents from different regions of the world and from different climatic zones. It is possible that the local market conditions at Abu-Hammour on the urban outskirts of Doha limited parasite species richness to the two species or, alternatively, the local rat population constitutes an isolated population into which other species have not yet been introduced. Further investigations of the parasites of rats from other urban and also rural sites in Qatar are therefore required.

\section{Acknowledgements}

We are most grateful to Dr Abdulla Al-Hamaq, Assistant Director for Public Health Affairs, Doha Municipality and Mr Mohamed Al-Kaabi, Head of the Department of Insect and Pest Control, for providing the field support. We also gratefully acknowledge the British Council in Qatar for facilitating and funding collaboration between Royal Holloway University of London and Qatar University.

\section{References}

Abu-Madi, M.A., Behnke, J.M., Lewis, J.W. \& Gilbert, F.S. (1998) Descriptive epidemiology of Heligmosomoides polygyrus in Apodemus sylvaticus from three contrasting habitats in south-east England. Journal of Helminthology 72, 93-100.

Abu-Madi, M.A., Behnke, J.M., Lewis, J.W. \& Gilbert, F.S. (2000) Seasonal and site specific variation in the component community structure of intestinal helminths in Apodemus sylvaticus from three contrasting habitats in south-east England. Journal of Helminthology 74, 7-15.

Acha, P. \& Szyfres, B. (1987) Zoonoses and communicable diseases common to man and animals. 2nd edn. Washington, DC, Pan American Health Organization.

Andreassen, J., Bennet-Jenkin, E.M. \& Bryant, C. (1999) Immunology and biochemistry of Hymenolepis diminuta. Advances in Parasitology 42, 223-275.

Behnke, J.M., Barnard, C., Hurst, J.L., McGregor, P.K., Gilbert, F. \& Lewis, J.W. (1993) The prevalence and intensity of infection with helminth parasites in Mus spretus from the Setubal Peninsula of Portugal. Journal of Helminthology 67, 115-122.

Behnke, J.M., Lewis, J.W., Mohd Zain, S.N. \& Gilbert, F.S. (1999) Helminth infections in Apodemus sylvaticus in southern England: interactive effects of host-age, sex and year on prevalence and abundance of infections. Journal of Helminthology 73, 31-44.

Behnke, J.M., Barnard, C., Mason, N., Harris, P.D., Sherif, N.E., Zalat, S. \& Gilbert, F.S. (2000) Intestinal helminths of spiny mice (Acomys cahirinus dimidiatus) from St. Katherine's Protectorate in the Sinai, Egypt. Journal of Helminthology 74, 31-43.

Brooks, J.E. \& Rowe, F.P. (1987) Vector control series: rodents, training and information guide. World Health Organization, WHO/VBC/87.949, 107 pp.

Bundy, D.A.P. (1988) Gender-dependent patterns of infection and disease. Parasitology Today 4, 186-189.

Chomel, B.B. (1992) Zoonoses of house pets other than dogs, cats and birds. Paediatric Infectious Diseases Journal 11, 479-487.

Crawley, M.T. (1993) GLIM for ecologists. Oxford, Blackwell Scientific Press.

Dash, K.M., Hall, E. \& Barger, I.A. (1988) The role of arithmetic and geometric mean worm egg counts in faecal egg count reduction tests and in monitoring strategic drenching programs in sheep. Australian Veterinary Journal 65, 66-68.

De Clercq, D., Sacko, M., Behnke, J.M., Gilbert, F., Dorny, P. \& Vercruysse, J. (1997) Failure of mebendazole in treatment of human hookworm infections in the Southern Region of Mali. American Journal of Tropical Medicine and Hygiene 57, 25-30.

Elliott, J.M. (1977) Some methods for the statistical analysis of samples of benthic invertebrates. Cumbria, UK, Freshwater Biological Association.

Erhardova-Kotrla, B. \& Daniel, M. (1970) Parasitic worms of small mammals from the region of the mountain regions of the Eastern Hindu Kush. Folia Parasitologica 17, 201-206.

Fahmy, M.A.M., Rifaat, M.A. \& Arafa, M.S. (1969) Helminthic infection of the brown rat, Ruttus norvegicus (Berkenhout, 1769) in U.A.R. Journal of the Egyptian Public Health Association 46, 147-153.

Greenberg, Z. (1969) Helminths of mammals and birds of Israel I. Helminths of Acomys spp. (Rodentia, Murinae). Israel Journal of Zoology 18, 25-38.

Gregory, R.D. (1992) On the interpretation of hostparasite ecology: Heligmosomoides polygyrus (Nematoda) in wild wood mouse (Apodemus sylvaticus) populations. Journal of Zoology 226, 109-121.

Haukisalmi, V., Henttonen, H. \& Tenora, F. (1988) Population dynamics of common are rare helminths in cyclic vole populations. Journal of Animal Ecology 57, 807-825.

Healing, T.D. \& Nowell, F. (1985) Diseases and parasites of woodland rodent populations. Symposia of the Zoological Society of London 55, 193-218.

Kansouh, A.S., El-Zemaity, M.S. \& Mikhail, M.W. (1990) Population density of domestic rodents and associates fleas at Dahshour, Giza governorate. Annals of Agricultural Science 35, 543-550.

Kisielewska, K. (1970) Ecological organization of intestinal helminth groupings in Clethrionomys glareolus (Schreb.) (Rodentia). V. Some questions concerning helminth groupings in the host individuals. Acta Parasitologica Polonica 17, 197-208.

Lewis, J.W. (1968) Studies on the helminth parasites of the long-tailed field mouse, Apodemus sylvaticus from Wales. Journal of Zoology 154, 287-312.

Lewis, J.W. (1987) Helminth parasites of British rodents and insectivores. Mammal Review 17, 81-93.

Lewis, J.W. \& Twigg, G.I. (1972) A study of the internal parasites of small rodents from woodland areas in Surrey. Journal of Zoology 166, 61-77.

Mafiana, C.F., Osho, M.B. \& Sam-Wobo, S. (1997) Gastrointestinal helminth parasites of the black rat 
(Rattus rattus) in Abeokuta, southwest Nigeria. Journal of Helminthology 71, 217-220.

Margolis, L., Esch, G.W., Holmes, J.C., Kuris, A.M. \& Schad, G.A. (1982) The use of ecological terms in parasitology (report of an ad hoc committee of The American Society of Parasitologists). Journal of Parasitology 68, 131-133.

Montgomery, S.S.J. \& Montgomery, W.I. (1990) Structure, stability and species interactions in helminth communities of wood mice Apodemus sylvaticus. International Journal for Parasitology 20, 225-242.

Morris, P. (1972) A review of mammalian age determination methods. Mammal Review 2, 69-104.

Myers, B.J., Kuntz, R.E. \& Wells, W.H. (1962) Helminth parasites of reptiles, birds, and mammals in Egypt VII. Check list of nematodes collected from 1948 to 1955. Canadian Journal of Zoology 40, 531-538.

Poulin, R. (1993) The disparity between observed and uniform distribution: a new look at parasite aggregation. International Journal for Parasitology 23, 937-944.

Read, C.P. (1967) Longevity of the tapeworm, Hymenolepis diminuta. Journal of Parasitology 53, 1055-1056.

Rifaat, M.A., Mohammed, A.H.H., Mahdi, A.H. \& Arafa, M.S. (1969) Some observations on ectoparasites infesting domestic and commensal rodents in U.A.R. Journal of the Egyptian Public Health Association 44, 97118.

Seng, L.T., Liat, L.B., Fong, Y.L. \& Krishnasamy, M. (1979) Parasite fauna of the house rat Rattus rattus diardii in Kuala Lumpur and nearby villages. Southeast Asian Journal of Tropical Medicine and Public Health 10, 122-126.
Seong, J.K., Huh, S., Lee, J.S. \& Oh, Y.S. (1995) Helminths in Rattus norvegicus in Chunchon, Korea. Korean Journal of Parasitology 33, 235-237.

Sinniah, B. (1979) Parasites of some rodents in Malaysia. Southeast Asian Journal of Tropical Medicine and Public Health 10, 115-121.

Tena, D., Simon, M.P., Gimeno, C., Pomata, M.T.P., Illescas, S., Amondarain, I., Gonzalez, A., Dominguez, J. \& Bisquert, J. (1998) Human infection with Hymenolepis diminuta: case report from Spain. Journal of Clinical Microbiology 36, 2375-2376.

Udonsi, J.K. (1989) Helminth parasites of wild populations of the black rat, Rattus rattus (L.), from urban, rural residential and other ecological areas of Nigeria. Acta Parasitologica Polonica 34, 107-116.

Webster, J.P. \& Macdonald, D.W. (1995) Parasites of wild brown rats (Rattus norvegicus) on UK farms. Parasitology 111, 247-255.

Welch, J.S. (1972) Parasitology field studies. Twenty Seventh Annual Report for the Queensland Institute of Medical Research, Brisbane (1971) Volume 24.

Werthein, G. \& Greenberg, Z. (1970) Notes on helminth parasites of myomorph rodents from Southern Sinai. Journal of Helminthology 44, 243-252.

Zakaria, M. \& Zaghloul, T.M. (1982) Parasitic infection of Rattus norvegicus in Kuwait. Proceedings of the First Symposium on Recent Advances in Rodent Control, Kuwait 136-143.

(Accepted 8 February 2001)

(C) CAB International, 2001 